\title{
Estimation of the effect of motorcycles on the capacity of signalized intersections
}

\author{
Estimação do efeito de motocicletas na capacidade de interseções \\ semaforizadas
}

\author{
Roberto Matheus Nunes Torquato ${ }^{1}$, Matheus Souza Carvalho Maciel ${ }^{2}$, \\ Manoel Mendonça de Castro Neto ${ }^{3}$
}

1Universidade Federal do Ceará, Ceará - Brasil, roberto.torquato@det.ufc.br

2Universidade Federal do Ceará, Ceará - Brasil, matheus.scmaciel97@gmail.com

3Universidade Federal do Ceará, Ceará - Brasil, manoel@det.ufc.br

\section{Recebido: \\ 17 de novembro de 2019 \\ Aceito para publicação: \\ 11 de janeiro de 2020 \\ Publicado: \\ 15 de dezembro de 2020 \\ Editor de área: \\ Sara Ferreira}

\section{Keywords:}

Urban traffic.

Traffic signal.

Passenger-car-equivalent.

Traffic capacity analysis.

\section{Palavras-chaves:}

Tráfego urbano.

Semáforo.

Equivalência ucp.

Análise de capacidade de tráfego.

DOI:10.14295/transportes.v28i5.2229

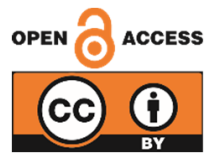

\begin{abstract}
The main objective of this paper is to estimate and evaluate the effect of motorcycles on signalized intersections. For this, variables that represent the presence of motorcycles in front of the first vehicle in the queue, between vehicles longitudinally, and between vehicles laterally (on virtual lane) were collected. The results showed that the average effect of a motorcycle positioned ahead or between vehicles on the start-up lost time is between 0.3 and $0.7 \mathrm{~s}$. However, there was no evidence that motorcycles on the virtual lane affects the vehicle queue discharge. Regarding the saturation headways, the results indicated that a motorcycle in front of a vehicle increases its discharge headway by $0.7 \mathrm{~s}$, an increase of $30 \%$. A $10 \%$ increase in the proportion of motorcycles decreases saturation flow by around $60 \mathrm{veh} / \mathrm{h}$. The passenger car equivalent factor for motorcycle obtained in this study was 0.21 , considering only the motorcycles positioned longitudinally between vehicles.
\end{abstract}

\begin{abstract}
RESUMO
O objetivo principal deste artigo é estimar e avaliar o efeito das motocicletas em interseç̧ões semaforizadas. Para isso, foram coletadas variáveis que representam a presença de motocicletas na frente do primeiro veículo na fila, entre os veículos longitudinalmente e entre veículos lateralmente (na faixa virtual). Os resultados mostram que o efeito médio de uma motocicleta posicionada à frente ou entre veículos no tempo perdido inicial está entre 0.3 e $0.7 \mathrm{~s}$. No entanto, não houve evidência de que motocicletas na faixa virtual afeta a descarga da fila de veículos. Em relação aos headways de saturação, os resultados indicam que uma motocicleta na frente de um veículo aumenta seu headway de descarga em $0.7 \mathrm{~s}$, um aumento de $30 \%$. Um aumento de $10 \%$ na proporção de motocicletas diminui o fluxo de saturação em cerca de $60 \mathrm{veh} / \mathrm{h}$. $O$ fator de equivalência de carros de passeio para motocicletas obtido neste estudo foi de 0.21 , considerando apenas as motocicletas posicionadas longitudinalmente entre veículos.
\end{abstract}

\section{INTRODUCTION}

In Brazil, although motorcycles account for around $26 \%$ of Brazil's and $49 \%$ of Ceara State vehicular fleet, according to 2019 data made available by the Brazilian National Traffic Department (DENATRAN), motorcycles generally are not considered in studies on capacity analysis of signalized intersections. Usually, the impact of motorcycles is ignored due to the assumption that their effect on the vehicle queue discharge, thus, on capacity, is insignificant. However, for analysis of signalized intersections, DENATRAN (2014) recommends a passenger car equivalent (PCE) factor of 0.33 for motorcycles. This value indicates that a motorcycle needs the equivalent of one third of the green time required for a passenger car to be served on a signalized 
intersection. It is worth highlighting a terminology aspect in this paper: following the Highway Capacity Manual - HCM (TRB, 2010) and other preeminent references, the term passenger car includes cars, SUVs, vans, minibuses, ambulances and two-axle, four-tire, single-unit urban cargo vehicles.

Considering the studies conducted in Brazil, the effect of motorcycles has been analyzed from the perspective of road safety (Mânica, 2007; Martins et al., 2013; Berger, 2014; Holz, 2014, Coutinho et al., 2015). Despite the shortage of national studies that address the effect of motorcycles on the capacity of signalized intersections, some international studies indicate that motorcycles can considerably impact traffic flow if they account for a significant proportion of the traffic demand (Nakatsuji et al., 2001; Mihn and Sano, 2003; Rongviriyapanich and Suppattrakul, 2005; Anusha et al., 2013, Radhakrishnan and Ramadurai, 2015).

According to the fleet data provided by DENATRAN, between 2009 and 2019, in Brazil, there was an increase of around $62 \%$ in the number of cars, while the increase in motorcycles was $87 \%$. Considering the physical and operational characteristics of motorcycles, in addition to having affordable purchase and maintenance costs for a large portion of the population, it is expected that there will be a continuing increase in the fleet of two-wheelest in Brazil.

Therefore, from the traffic engineering perspective, it is important to identify and characterize the effects of motorcycles, not only on road safety, but also on road capacity in Brazilian cities. Therefore, the main objective of this article is to estimate the effect of motorcycles on the capacity of signalized intersections, specifically on start-up lost time (li), on saturation discharge headway $\left(h_{d s}\right)$, and on saturation flow $(S)$. A PCE factor for motorcycles will also be estimated.

\section{THE EFFECT OF MOTORCYCLES ON SIGNALIZED INTERSECTION OPERATIONS}

In signalized intersections, traffic platoons compete for spaces. The total available time within an hour must be carefully split in order to maximize capacity and minimize delays on the intersection (Elefteriadou, 2014). In addition to the green time, which is calculated considering the demands of the conflicting movements, other two important factors that contribute to the capacity of signalized intersections are $l_{1}$ and $S$.

Several studies have been conducted to identify and quantify the factors that influence the capacity of signalized intersections. Bonneson (1992) evaluated the effect of the volume of vehicles per cycle on queue discharge. Le et al (2000) estimated the effect of land-use on $h_{d s .} \mathrm{Lu}$ and Pernía (2000) analyzed the effect of the proportion of elderly people on $l_{1}$ and on saturation headways. Agbolosu-Amison (2004) analyzed the effect of climate on $l_{1}$ and on saturation headways. Khosla and Williams (2006) evaluated the effect of green time on queue discharge. The HCM (TRB, 2010) model to estimate $S$ considers the effect of several factors such as lane width, grade, presence of parking lots and bus stops, and turning movements.

The studies that aimed to measure and evaluate the effect of motorcycles on traffic flow were mainly conducted in Asian countries, where the fleet predominantly consists of motorcycles. One of the pioneering studies that evaluated the effect of motorcycles on $l_{1}$ and $S$ was developed by Nakatsuji et al. (2001), using data collected in Hanoi and Bangkok.

Those authors proposed three configurations to evaluate the effect of motorcycles on $l_{1}$ : cycles with no motorcycles, with a row of motorcycles in front of the first vehicle, and with two rows of motorcycles in front of the first vehicle. The effect of motorcycles on $S$ was investigated considering the relative position of motorcycles in relation to vehicles. The authors applied 
statistical tools such as tests for the mean, variance and regression models.

In the absence of motorcycles in front of the first vehicle in the queue, the $l_{1}$ obtained at the Hanoi intersection presented an average of $3.3 \mathrm{~s}$ and standard deviation of $1.3 \mathrm{~s}$. In the scenario of two rows of motorcycles, the average was $5.7 \mathrm{~s}$ and the standard deviation was $1.4 \mathrm{~s}$. The results showed a significant effect of motorcycles on $l_{1}$.

Regarding the saturation flow regime, the results indicated mean values of $h_{d s}$ of 2.1 and 1.9 $s$ for Hanoi and Bangkok, respectively, under the scenario with no motorcycles. When there was a motorcycle longitudinally between consecutive vehicles, these values were 3.4 and $2.9 \mathrm{~s}$. Therefore, the authors concluded that the relative position of motorcycles has a significant impact on $S$, considering that there was a decrease of until $40 \%$ when there was no motorcycle between two vehicles.

The main objective of Minh and Sano (2003) was to evaluate the effect of motorcycles on the capacity of signalized intersections in Hanoi and Bangkok. To measure the effect on $l_{1}$, quadratic regressions were performed using $l_{1}$ as predicted variable and the volume of motorcycles in front of the first vehicle as explanatory variable. In order to assess the effect of motorcycles on $S$, linear regressions were developed having $h_{d s}$ as dependent variable and the volume of motorcycles as independent variable.

As for the effect of motorcycles on $l_{1}$, the observed data ranged from 0 to 6 motorcycles in front of the first vehicle and $l_{1}$ from 2,0 to $8,0 \mathrm{~s}$. The quadratic regressions had $\mathrm{R}^{2}$ of 0.49 for the intersection located in Hanoi and 0.63 for the one in Bangkok. The authors did not evaluate the values of the model parameters and did not present their statistical significance nor confidence intervals. That evaluation is important, as it is the basis for the interpretation of the influence of motorcycles.

The results of the regression analyses for $h_{d s}$ indicated $\mathrm{R}^{2}$ of 0.79 for Hanoi and 0.60 for Bangkok. The intercepts indicate the average values of the headways when there are no motorcycles between vehicles, and they were 2.11 and 2.03 s respectively for Hanoi and Bangkok. The slope coefficients represent the average increase on headway for each motorcycle between vehicles. The obtained slope coefficients were $0.51 \mathrm{~s}$ and $0.60 \mathrm{~s}$ respectively for the cities of Hanoi and Bangkok.

Nakatsuji et al. (2001) and Mihn and Sano (2003) assessed the effect of individual motorcycles in each car discharge headway during the saturation flow regime, also not making a distinction between the types of vehicles (passenger car or heavy vehicles). Thus, broader analyses were not conducted such as evaluate the effect of the proportion of motorcycles on the saturation headway of each cycle. In the statistical analyses performed by the authors, the values of the lower and upper limits of each coefficient were not presented and discussed, nor were statistical tests performed to check the premises of the fitted linear regression models.

Mihn and Sano (2003) also estimated the PCE factor for motorcycles applying multiple linear regression models to obtain the equivalence factors of motorcycles in passenger cars. The regression model had the saturated green time of a cycle as the response variable and the volumes of each vehicle type (motorcycle, passenger car and heavy vehicle) passing through the stop bar during a cycle as the explanatory variables. The saturated green time of a cycle is obtained by adding the vehicle headways during the saturation flow regime of the cycle. The PCE factor for motorcycle is estimated by the ratio of the regression coefficient of the motorcycle variable and the coefficient of the passenger car variable. The results showed PCE factors for motorcycles of 0.24 and 0.18 for Hanoi and Bangkok, respectively. 
As presented in this section, several studies have analyzed the effect of motorcycles on traffic. However, no statistical studies investigating the influence of motorcycles on general traffic in Brazilian cities were found in the literature, which justifies the relevance of this study.

\section{METHOD}

The method used in this research is shown in Figure 1. It consists of four analysis topics: $l_{1}, h_{d s}$, $S$, and PCE. Each topic has three common steps: variables definition, exploratory data analysis, and model development and analysis.

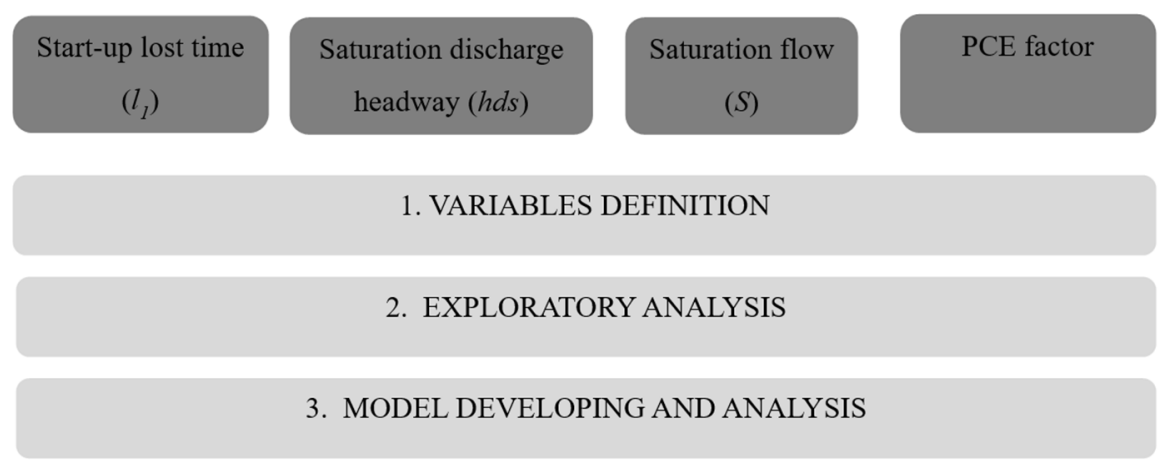

Figure 1. Research Method

The first topic of analysis assesses the effect of the following three motorcycle positions on $l_{1}$ : by the stop bar; longitudinally between vehicles; and laterally between vehicles, that is, on the virtual lane. A hypothesis of this research is the higher the volumes of motorcycles on these three positions the higher is $l_{1}$. In this research it was not possible to analyze the effect of motorcycles on the clearance lost time $\left(l_{2}\right)$, due to two reasons. First, on the signal red time all motorcycles concentrated almost exclusively near the first vehicles in the queue. Second, there were very few saturated greens, so there were very few observations with motorcycles near the end of the queue, which makes it unfeasible to estimate $l_{2}$ with the adequate statistical rigor.

The second analysis topic evaluates the effect of motorcycles positioned longitudinally between two vehicles on $h_{d s}$. The hypothesis is that higher volumes of motorcycles in this position lead to greater $h_{d s}$.

The third topic analyzes the effect of the proportion of motorcycles positioned longitudinally between vehicles during the saturation flow regime on $S$. The hypothesis is that the higher the proportions of motorcycles, the lower $S$. The fourth topic estimates and analyzes the PCE factor for motorcycles for the studied signalized intersection.

As mentioned before, there are three common steps for each topic of analysis: variables definition, exploratory analysis, and model development and analysis. The first step defines the variables necessary to achieve the objectives of each analysis topic. The second step brings the exploratory analysis of the collected variables, which includes correlation analysis to verify the hypotheses raised in each topic.

The last step consists of developing regression models and analyzing the point and the 95\% confidence interval estimates of the coefficients, their statistical significance, the $\mathrm{R}^{2}$, as well as the verification of the model assumptions. The regression analysis estimates the average effect that a unit change in a variable related to motorcycles has on the dependent variables, which shows evidences about the effects of motorcycles on the capacity of signalized intersections. 
The data for this study were collected by surveillance cameras provided by the Fortaleza Advanced Traffic Control Center (CTAFOR), on the eastbound link of the intersection of Bernardo Manuel Avenue and Doutor Silas Munguba Avenue, located in the city of Fortaleza, Brazil. The studied link has two traffic lanes. However, for the purpose of concision, this paper presents the results only for the right lane, as it had more observations of heavy vehicles, which allowed more robust results. In the right lane, 199 traffic signal cycles were collected which resulted in 1,816 vehicle discharge headways.

For the observation of headways, the rear axle of the vehicles was used as the reference, as indicated by DENATRAN (2014). It was noticed that, using the front axle as a reference, generally the headway of the first vehicle was considerably smaller than the second's, due to the proximity of the first vehicle's front axle to the stopping bar. This finding is not supported by literature, in which the first discharge headway is generally the highest.

\section{START-UP LOST TIME}

\subsection{Variables definition}

To achieve the objective of the first analysis topic, related to $l_{1}$, the following variables were collected. They are illustrated in Figure 2.

- $\quad H 4_{j}$ : cumulative headway (s) of the fourth vehicle in the queue, on cycle $j$;

- $\quad V m f_{j}$ : volume of motorcycles in front of the first vehicle in the queue, in cycle $j$;

- $V m b v_{j}$ : total number of motorcycles travelling longitudinally between the first and the fourth vehicle in the queue, during queue discharge of cycle $j$;

- Pmvlj: queue position of the last vehicle that is neared by a motorcycle on the virtual lane, on cycle $j$;

- $\quad V h v_{j}$ : volume of heavy vehicles (in red) until the fourth vehicle in the queue, of cycle j.

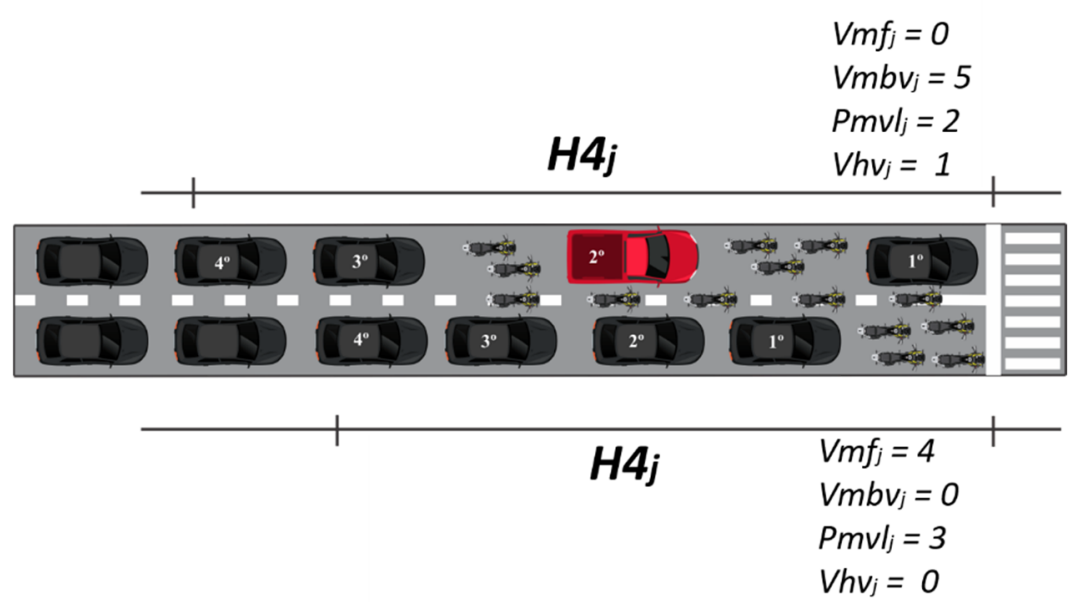

Figure 2. Illustration of values for variables $H 4_{j}, V m f_{j}, V m b v_{j}, P m v l_{j}$ e $V h v_{j}$

\subsection{Exploratory Analysis}

In order to identify the correlations between the variables defined to analyze the effect of motorcycles on $l_{1}$, a correlation matrix (Figure 3) was generated, including the values of Pearson's coefficients $(r)$ and their statistical significance, in addition to the scatter plots between variables with the fitted regression line and the histogram of each variable. The sample size is 199, which is the number of signal cycles observed for the right lane. 


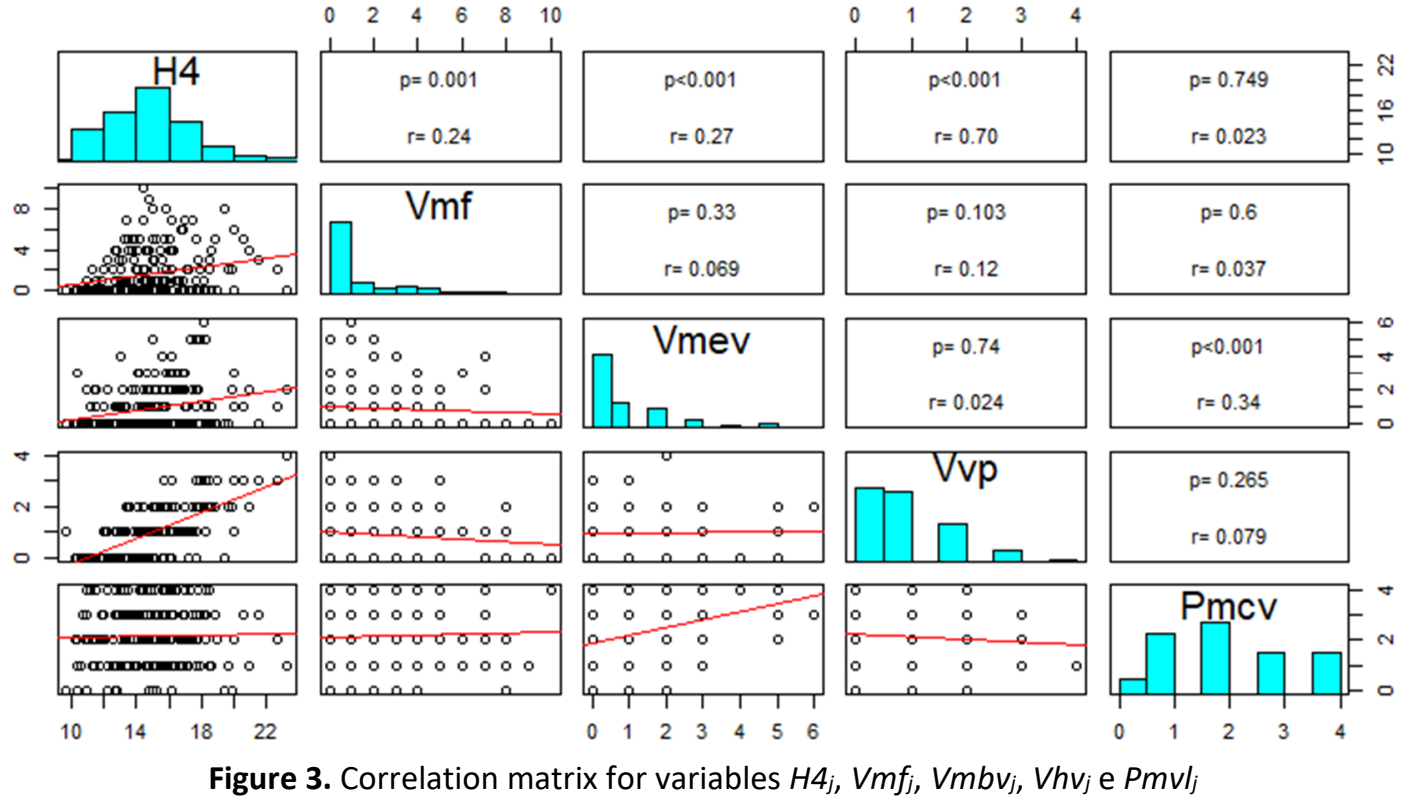

It is possible to identify a low, but statistically significant, positive correlation between the dependent variable $\left({ }^{H} 4_{j}\right)$ and $V m f_{j}$ and $V m b v_{j}$, considering the values of $\mathrm{r}=0.24$ and 0.27 , respectively. A stronger positive linear relationship ( $\mathrm{r}=0.70$ ) between $H 4_{j}$ and $V h v_{j}$ was found. Finally, the correlation between $\mathrm{H}_{j}$ and $\mathrm{Pmvl}_{j}$ was not statistically significant.

The results showed evidences of positive relationship, even though low, between the volume of motorcycles ahead of the first vehicle and the cumulative headway of the $4^{\text {th }}$ vehicle, thus with $l_{1}$. However, the results showed no evidence of impact of motorcycles located on the virtual lane on $H 4 j$. According to the results, the factor that mostly impacts $l_{1}$ is the volume of heavy vehicles until the $4^{\text {th }}$ vehicle in the queue.

\subsection{Model developing and analysis}

To evaluate the effect of motorcycles on $l_{1}$, linear regression models were fitted having $H 4_{j}$ as response variable and $V m f_{j}, V m b v_{j}, P m v l_{j}$ and $V h v_{j}$ as predictors. Table 1 presents the point and 95\% confidence interval estimates of the coefficients and their statistical significance, in addition to $\mathrm{R}^{2}$ and sample size.

'The regression results confirm the conclusions of the correlation analysis, that there is no significant correlation between $\mathrm{H}_{j} \mathrm{j}$ and $\mathrm{Pmvl}_{j}$, as the coefficient of $\mathrm{Pmvl}_{j}$ is not statistically significant. The intercept represents the sum of the headways of the first four vehicles - passenger cars - when no motorcycles are present.

Table 1 - Linear regression results for $\mathrm{H} 4$.

\begin{tabular}{lllllll}
\hline Coeficcient & Value & P-Value & Lower Limit & Upper Limit & $\mathbf{R}^{\mathbf{2}}$ & $\mathbf{N}$ \\
\hline Intercept & 11.9 & $<0.1 \%$ & 11.4 & 12.5 & & \\
$V_{m f}$ & 0.4 & $<0.1 \%$ & 0.3 & 0.5 & & \\
Vmbv $_{j}$ & 0.6 & $<0.1 \%$ & 0.4 & 0.7 & 0.66 & 199 \\
Pmvl $_{j}$ & -0.1 & $52 \%$ & -0.2 & 0.1 & & \\
$V_{h v_{j}}$ & 2,0 & $<0.1 \%$ & 1.8 & 2.2 & & \\
\hline
\end{tabular}


The variable $V m f_{j}$ has a coefficient of $0.4 \mathrm{~s}$ and confidence interval of [0.3-0.5 s]. This indicates that a motorcycle in front of the first vehicle increases $H 4_{j}$ - thus $l_{1}-$ by $0.4 \mathrm{~s}$, on average. The variable $\mathrm{Vmbv}_{j}$ has a coefficient of $0.6 \mathrm{~s}$ and confidence interval of [0.4-0.7 s]. It means that a motorcycle between vehicles increases, on average, $0.6 \mathrm{~s}$ to $H 4 j$, thus to $l_{1}$.

$V h v_{j}$ has a coefficient $2.0 \mathrm{~s}$ and confidence interval of [1.8-2.2 s]. Therefore, the average effect of a heavy vehicle is greater than that of a motorcycle, which partially explains the greater correlation between $V h v_{j}$ and $H 4_{j}$, as previously presented. The coefficient of determination indicates that $66 \%$ of $H 4 j$ variation could be explained by the variables that represent motorcycles and heavy vehicles.

In order to verify the regression modelling assumptions, tests for independence (DurbinWatson), normality (Kolmogorov-Smirnov), and homoscedasticity (Breush-Pagan) on the residuals were performed. The p-values were 0.98, 0.69, and 0.05 , respectively for independence, normality and homoscedasticity. Therefore, the assumptions of independence, normality and homoscedasticity were not rejected.

\section{SATURATION DISCHARGE HEADWAYS}

\subsection{Variables definition}

To achieve the objective of the second analysis topic, about $h_{d s}$, the following variables were collected. They are illustrated in Figure 3.

- hdsij: saturation discharge headway (s) of a passenger car or a heavy vehicle in the queue position $j$ during cycle $i$. The saturation regime was considered beginning from the $5^{\text {o }}$ vehicle in the queue;

- $V m_{i j}$ : volume of motorcycles ahead of the $\mathrm{j}^{\text {th }}$ vehicle in the queue during the saturation flow regime of cycle $i$. For this variable, motorcycles on the virtual lane were not considered;

- $t v_{i j:}$ a binary variable that represents the type of vehicle in the queue position $j$ during cycle $i$. It is 0 for passenger car and 1 for heavy vehicle.

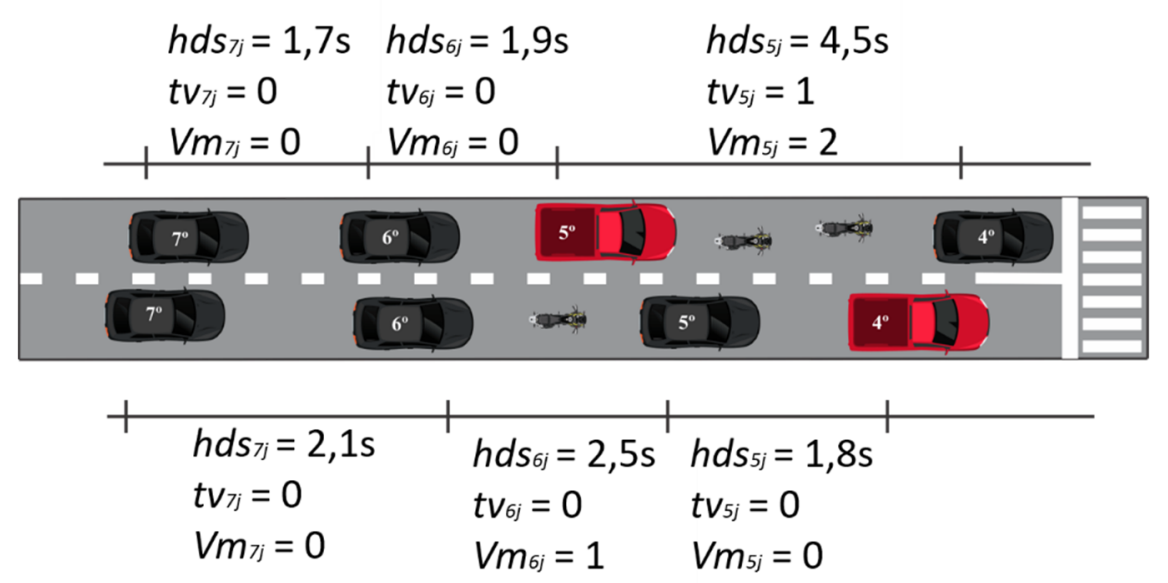

Figure 4. Illustration of values for variables hdsij, Vmij and tvij.

\subsection{Exploratory analysis}

In order to identify the correlations between the variables defined to analyze the effect of the 
motorcycles on the saturation discharge headways, Figure 5 shows the correlation coefficients and their statistical significance, as well as the scatter plots between the variables with the fitted regression line, and the histogram of each variable. A total of 1020 observations were obtained, which represent the number of saturation discharge headways collected on the right lane.

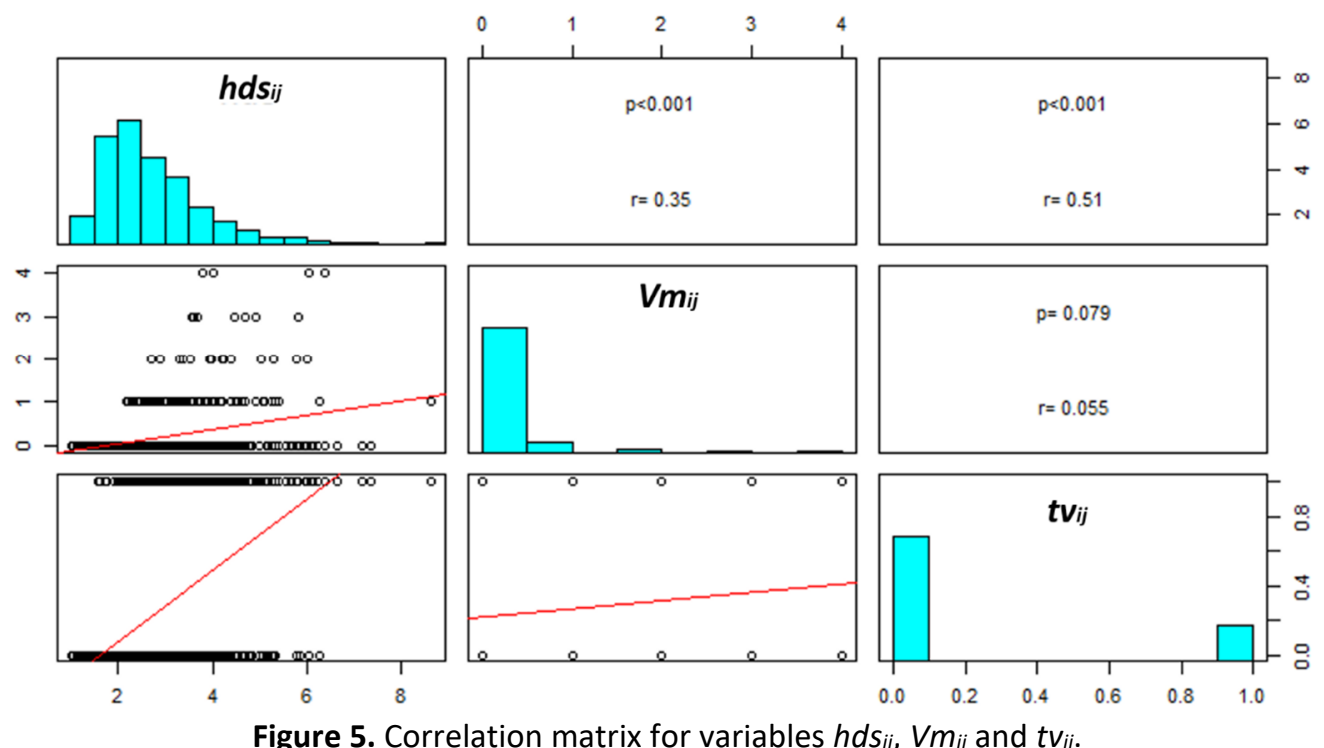

The correlation between $h d s_{i j}$ and $V m_{i j} r=0.35$, statistically significant, indicates a positive linear relationship with moderate intensity between these variables. Variables $h d s_{i j}$ and $t v_{i j}$ also had a statistically significant correlation $(r=0.51)$ which suggests a positive, moderate linear relationship between saturation discharge headway and vehicle type.

\subsection{Model developing and analysis}

To evaluate the effect of motorcycles on the saturation discharge headway, linear regression models were fitted having $h d s_{i j}$ as predicted variable and $V m_{i j}$ and $t v_{i j}$ as predictors. Table 2 presents the point and the $95 \%$ confidence interval estimates of the parameters, their statistical significance, $\mathrm{R}^{2}$, and sample size.

Table 2 - Linear regression results for $h d s_{i j}$

\begin{tabular}{lllllll}
\hline Coeficcients & Value & P-value & Lower Limit & Upper Limit & $\mathbf{R}^{\mathbf{2}}$ & $\mathbf{N}$ \\
\hline Intercept & 2.3 & $<0.1 \%$ & 2.3 & 2.4 & & \\
$V m_{i j}$ & 0.7 & $<0.1 \%$ & 0.6 & 0.8 & 0.37 & 1020 \\
$t v_{i j}$ & 1.2 & $<0.1 \%$ & 1.1 & 1.3 & & \\
\hline
\end{tabular}

All coefficients are statistically significant. The intercept (2.3 s) represents the average saturation discharge headway of passenger cars, having confidence interval [2.3-2.4 s]. The $t v_{i j}$ coefficient $(1.2 \mathrm{~s})$ represents the average increase if the vehicle is a truck or a bus. Therefore, a heavy vehicle has an average saturation discharge headway of $3.5 \mathrm{~s}$. The $t v_{i j}$ confidence interval is $[1.1-1.3 \mathrm{~s}]$.

The $V m_{i j}$ coefficient value is $0.7 \mathrm{~s}$. Therefore, according to the model, a motorcycle in front of a passenger car increases its saturation discharge headway from 2.3 to 3.0 s on average, an increase of approximately $30 \%$. In case the vehicle is a heavy vehicle, a motorcycle ahead of it 
causes an average increase of approximately $20 \%$. The $\mathrm{R}^{2}$ means that $37 \%$ of the variation in the saturation discharge headways can be explained by the type of vehicle and by the number of motorcycles in front of it.

To assess model compliance with the regression premises, tests of independence (DurbinWatson), normality (Kolmogorov-Smirnov), and homoscedasticity (Breush-Pagan) on the residuals were performed. The p-values were 0.65 , less than 0.01 , and less than 0.01 respectively for independence, normality and homoscedasticity. Therefore, it is concluded that the assumptions of normality and homoscedasticity were not met, hence the statistical inferences are not valid and the coefficients are no longer the best unbiased estimators; however, they keep the lack of bias and the consistency properties of the least squares method.

\section{SATURATION FLOW}

\subsection{Variables definition}

In order to achieve the objective of the third analysis topic, related to $S$, the following variables were collected. They are illustrated in Figure 6.

- $h s_{j}$ : saturation headway (s) of cycle $j$, computed as the average of all $h d s_{i j}$ of cycle $j$;

- $S_{j}$ : saturation flow (veh/h) of cycle $j$, computed as the ratio $3600 / h s_{j}$;

- $\quad p_{j}$ : percentage of motorcycles, of cycle $j$, between consecutive vehicles under the saturation discharge regime, considering the volume of passenger cars $\left(V p c_{j}\right)$ and of heavy vehicles $\left(V h v_{j}\right)$ on cycle $j$.

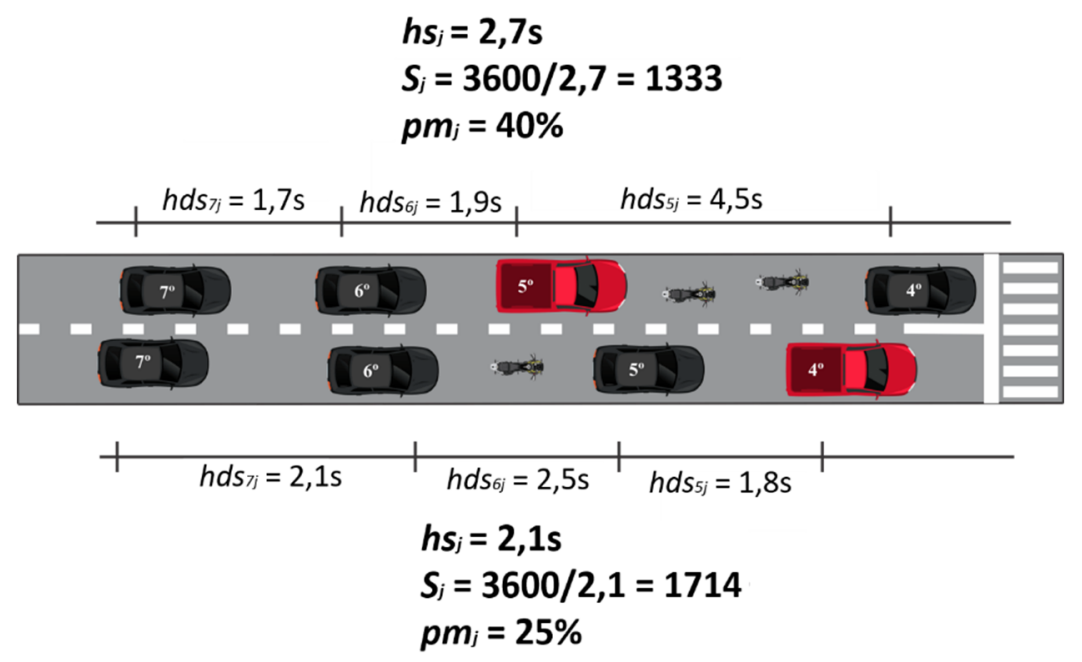

Figure 6. Illustration of values for variables $h s_{j}, S_{j}$ and $p m_{j}$

\subsection{Exploratory analysis}

For the purpose of identifying the correlations between the variables defined to analyze the effect of the motorcycles on $S$, Figure 7 shows the correlation coefficient and its statistical significance, as well as the scatter plots between the variables with the fitted regression line, and the histogram of each variable. The sample size is 199 , which is the number of signal cycles observed. 

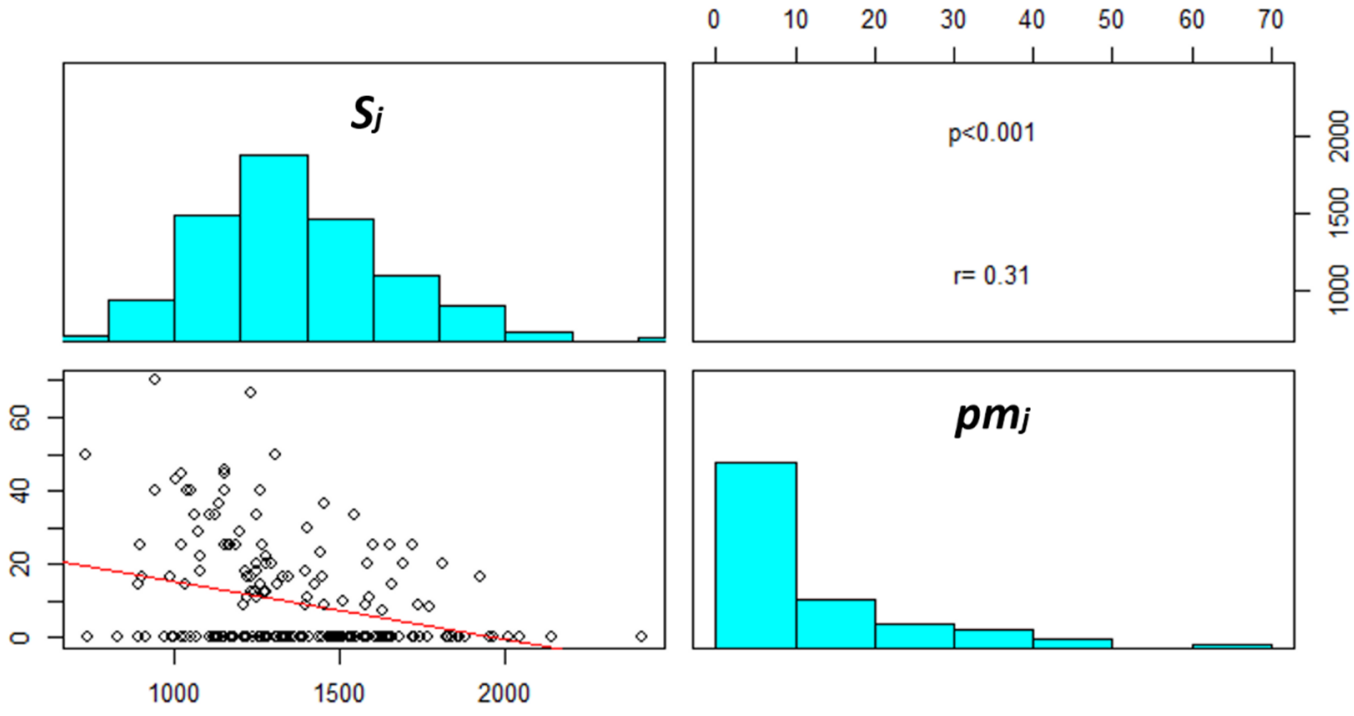

Figure 7. Correlation matrix for variables $S_{j}$ and $p m_{j}$

The statistically significant correlation between $S_{j}$ and $p m_{j} r=0.31$ suggests a positive linear relationship with low intensity between the saturation flow and the percentage of motorcycles on the right lane - the strength of this correlation is similar to that obtained on the left lane. In the scatter plot, even in the absence of motorcycles $\left(p m_{j}=0\right)$ there are values of $S$ as low as 1000 vehicles per hour, because there are other factors that influence the saturation discharge of vehicles.

\subsection{Model developing and analysis}

In order to evaluate the effect of motorcycles on saturation flow, linear regression models were fitted having $S$ as response variable and $p m_{j}$ as predictor. Table 3 presents the point and the $95 \%$ confidence interval estimates of the coefficients and their statistical significance, in addition to $\mathrm{R}^{2}$ and number of observations.

Table 3 - Linear regression results for $\mathrm{Sj}$

\begin{tabular}{lllllll}
\hline Coeficientes & Value & P-value & Lower Limit & Upper Limit & $\mathbf{R}^{\mathbf{2}}$ & $\mathbf{N}$ \\
\hline Intercept & 1416 & $<0.1 \%$ & 1371 & 1461 & \multirow{2}{*}{0,07} & \multirow{2}{*}{199} \\
pm $_{j}$ & $-6,0$ & $<0.1 \%$ & -8.6 & -3.4 & & \\
\hline
\end{tabular}

The coefficients are statistically significant. The intercept $(1416 \mathrm{veh} / \mathrm{h})$ indicates the estimated saturation flow on the right lane when there are no motorcycles positioned longitudinally during the saturation regime. The confidence interval is [1371 and $1461 \mathrm{veh} / \mathrm{h}$ ]. The value of the intercept corresponds to an average $h s j$ of approximately $2.5 \mathrm{~s}$.

The point estimate of the $p m_{j}$ coefficient is $-6.0 \mathrm{veh} / \mathrm{h}$; which represents the reduction in $S$ caused by a $1 \%$ increase in the proportion of motorcycles. Therefore, according to the model, a proportion of $50 \%$ of motorcycles in a traffic light cycle results in $S$ of $1489 \mathrm{veh} / \mathrm{h}$, a reduction of $21 \%$ when compared to the situation with no motorcycles. The coefficient's confidence interval is [-8.6 to $-3.4 \mathrm{veh} / \mathrm{h}]$. The coefficient of determination indicated that $7 \%$ of the variation in $S$ of each cycle could be explained by the proportion of motorcycles observed during the saturation regime. 
In order to verify the regression modelling assumptions, tests for independence (DurbinWatson), normality (Kolmogorov-Smirnov), and homoscedasticity (Breush-Pagan) on the residuals were performed. The p-values were $0.94,0.45$ and 0,02 , respectively for independence, normality and homoscedasticity. Therefore, the assumptions of homoscedasticity were not met, hence the statistical inferences are not valid, and the coefficients are no longer the best unbiased estimators; however, they keep the lack of bias and consistency properties of the least squares method.

\section{PASSENGER CAR EQUIVALENT FACTOR}

\subsection{Variables definition}

To conduct the analysis on PCE factor for motorcycles, the following variables were collected:

- $g s_{j}$ : green time during the saturation flow regime of cycle $j$, computed as the sum of all $h d_{i j}$ of cycle $j$;

- $\quad V m_{j}$ : volume of motorcycles travelling longitudinally among vehicles on cycle $j$, during the saturation flow regime;

- $\quad V p c_{j}$ : volume of passenger cars on cycle $j$, during the saturation flow regime;

- $\quad V h v_{j}$ : volume of heavy vehicles on cycle $j$, during the saturation flow regime.

\subsection{Exploratory Analysis}

To identify the correlations between the variables defined to estimate the PCE factor, a correlation matrix (Figure 8) was generated, including the values of the correlation coefficients $(r)$ and their statistical significance, in addition to the scatterplots between the variables with the fitted regression line, and the histogram of each variable. The sample size is 199 , which is the number of signal cycles observed for the right lane
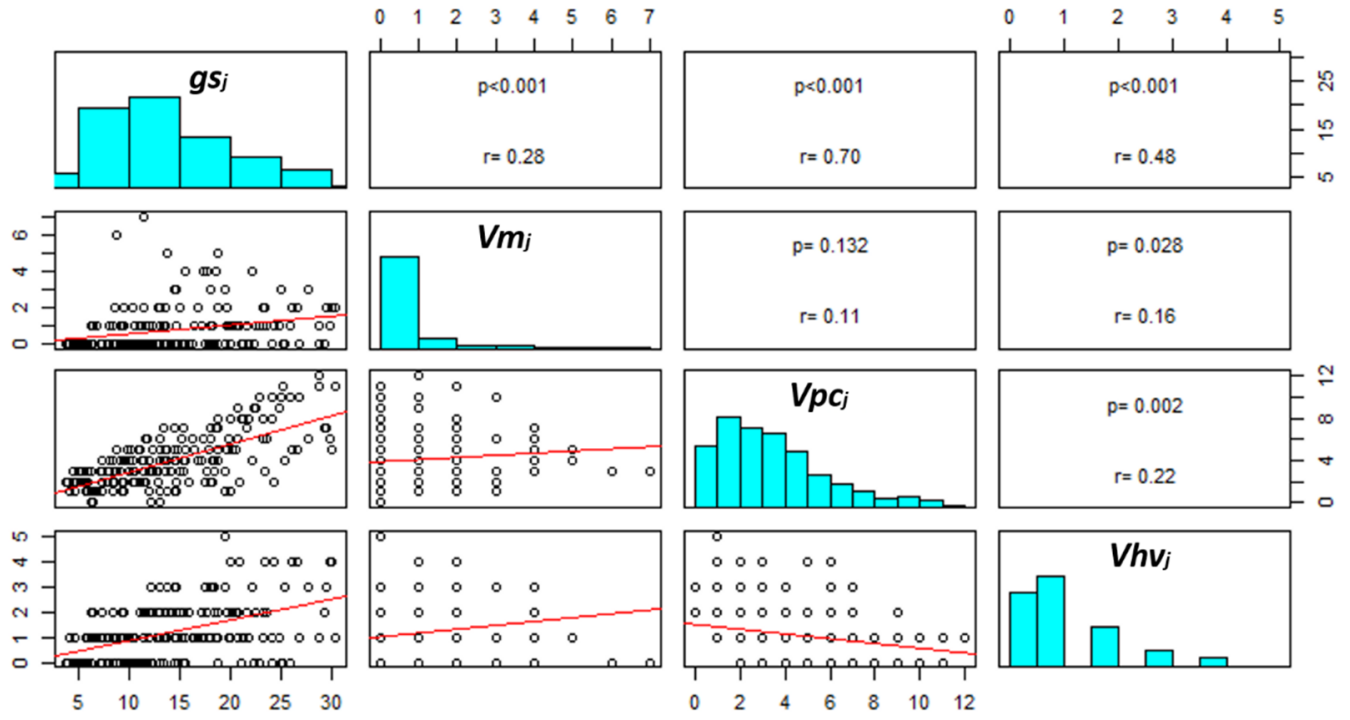

Figure 8. Correlation matrix for variables $g s_{j}, V m_{j}, V p c_{j}$ and $V h v_{j}$

The correlation coefficient between $g s_{j}$ and $V m_{j}, \mathrm{r}=0.28$, statistically significant, indicates a positive linear relationship with low intensity between the variables that represent the saturated green time and the volume of motorcycles travelling longitudinally among vehicles during 
the saturation regime. The correlation coefficient between $g s_{j}$ and $V p c_{j} \mathrm{r}=0.70$, statistically significant, indicates a strong positive linear relationship between the variables that represent the saturated green time and the volume of passenger cars during the saturation regime. As for $g s_{j}$ and $V h v_{j}, \mathrm{r}=0.48$, also statistically significant, shows a moderate positive linear relationship between these variables.

\subsection{Model developing and analysis}

In order to obtain and evaluate the PCE factor for motorcycles, linear regression was performed considering $g s_{j}$ as the response variable and $V m_{j}, V p c_{j}$, and $V h v_{j}$ as predictors. The point and the 95\% confidence interval estimates of the coefficients and their statistical significance, in addition to $\mathrm{R}^{2}$ and sample size, are shown in Table 4.

Table 4 - Linear Regression Results for $g s_{j}$

\begin{tabular}{lllllll}
\hline Coefficient & Value & P-value & Lower Limit & Upper Limit & $\mathbf{R}^{\mathbf{2}}$ & $\mathbf{N}$ \\
\hline Intercept & 0.4 & $19.5 \%$ & -0.2 & 1,0 & & \\
$V p c_{j}$ & 2.2 & $<0.1 \%$ & 2.1 & 2.3 & 0.94 & 199 \\
$V h v_{j}$ & 3.8 & $<0.1 \%$ & 3.6 & 4.1 & & \\
$V m_{j}$ & 0.5 & $<0.1 \%$ & 0.3 & 0.7 & & \\
\hline
\end{tabular}

All coefficients, except for the intercept, were statistically significant. This fact that the intercept is not significant is consistent with its physical meaning - there is no saturated green time when there is no vehicle. The coefficient for $V m_{j}$ was $0.5 \mathrm{~s}$, with confidence interval [0.3-0.7 s], whereas the coefficient for $V p c_{j}$ was $2.2 \mathrm{~s}$, with confidence interval [2.1-2.3 s].

Dividing $V m j$ by the $V p c_{j}$, results in a PCE factor of 0.21 , which means that approximately 5 motorcycles positioned longitudinally among vehicles, during the saturation flow regime, have a similar effect of 1 passenger car on road capacity. The result is different from what is recommended by DENATRAN (2014), which suggests a PCE factor for motorcycles of 0.33, which means that 3 motorcycles have an effect equal to that of 1 passenger car. It is worth mentioning that the presented analysis ignores motorcycles on the virtual lane, given that the results of $l_{1}$ indicated that motorcycles in the virtual lane did not affect the capacity of the studied intersection link. The $\mathrm{R}^{2}$ means that $94 \%$ of the variation of the saturated green time of a cycle can be explained by its volumes of passenger cars, heavy vehicles, and motorcycles.

For the purpose of verifying the regression modelling assumptions, tests for independence (Durbin-Watson), normality (Kolmogorov-Smirnov), and homoscedasticity (Breush-Pagan) on the residuals were performed. The p-values were $0.44,0.70$, and 0.08 , respectively for independence, normality and homoscedasticity. Therefore, the assumptions of independence, normality and homoscedasticity are not rejected.

\section{CONCLUSIONS}

Although the literature presents some publications on the effect of motorcycles on the capacity of signalized intersections from the perspective of homogeneous traffic, there were no such studies conducted in traffic conditions such as found in Brazilian cities.

To assess the effects of motorcycles on the capacity of signalized intersections, the main objective of this research, the study was divided into four topics: start-up lost time $\left(l_{1}\right)$, saturation discharge headway (hds), saturation flow (S) and passenger car equivalent (PCE) 
factor for motorcycles. The research method was divided in three steps: variables definition, exploratory analysis, and model development and analysis.

During the exploratory analysis, in which the correlations between the variables of each analysis topic were assessed, the degree to which the variables related to each other was identified, which allowed the assessment of the hypotheses underlining each regression analysis. As for $l_{1}$, the dependent variable $H 4$ j showed a low positive correlation with the variables that represent the volume of motorcycles in front of the first vehicle $\left(V m f_{j}\right)$ and the volume of motorcycles longitudinally between vehicles $\left(V m b v_{j}\right)$, and a high positive correlation with the volume of heavy vehicles $\left(V h v_{j}\right)$. There was no statistically significant correlation between $H 4_{j}$ and the variable that represents the presence of motorcycles on the virtual lane $\left(P m v l_{j}\right)$. With these results, the hypotheses that motorcycles longitudinally between vehicles and in front of the first vehicle results in higher $l_{1}$ were reinforced, whereas the hypothesis of the impact of motorcycles on the virtual lane was rejected.

Regarding the correlation analysis of the saturation discharge headways, $h d s_{i j}$ showed a moderate positive correlation with the variable that represents the volume of motorcycles positioned longitudinally in front of the vehicles $\left(v m_{i j}\right)$. This result strengths the hypothesis that higher volumes of motorcycles between vehicles result in higher values of $h d s_{i j}$.

In the correlation analysis regarding the saturation flow, $S_{j}$ presented a low negative correlation with the variable that represents the proportion of motorcycles positioned longitudinally between vehicles during the saturation regime $\left(p m_{j}\right)$. The scatterplot showed that even in conditions of absence of motorcycles $\left(p m_{j}=0\right)$, there are low values of $S$ (close to 1000 vehicles per hour, for example), indicating that there are other factors that significantly influence the discharge headways of the vehicles during the saturation flow regime. The results emphasize the hypothesis that higher proportions of motorcycles result in lower $S$ although it does not appear to be a factor that impacts it strongly.

In the linear regression step on $l_{1}$ in both traffic lanes, the average effect of a motorcycle positioned in front of the first vehicle and between vehicles on $l_{1}$ was between 0.3 and $0.7 \mathrm{~s}$. There was no statistical significance in the parameter that represents motorcycles on the virtual lane, therefore there was no evidence that motorcycles positioned in the virtual lane affects vehicle discharge. Tests of independence, normality and homoscedasticity of the residuals did not reject these model assumptions.

As for the results of the regression analysis of the saturation discharge headways $h d s_{i j}$, it was concluded that a motorcycle in front of a vehicle increases its saturation headway between 0.6 and $0.8 \mathrm{~s}$. This value represents, for a passenger car, an increase of about $30 \%$ in the time it takes to be served by the intersection. As for the regression assumptions, the hypotheses of normality and homoscedasticity were rejected. Therefore, the inferences are not valid, and the coefficients are no longer the best unbiased linear estimators; however, they keep properties of absence of bias and consistency of the least squares method.

The regression analysis on saturation flow $(S)$ indicates that, on average, an 1\% increase in the proportion of motorcycles decreases $S$ by between 3.4 and 8.6 vehicles per hour, 6.0 being the mean value. The regression model also indicates that the proportion of motorcycles explains about $7 \%$ of $S$ variation of the cycles. Independence, normality and homoscedasticity tests were conducted, and the results indicated that only the homoscedasticity premise was violated. Thus, the coefficients are no longer the best unbiased estimators, but they keep the properties of no bias and consistency of the least square estimators. 
The regression analysis on passenger car equivalent (PCE) factor resulted in a PCE factor for motorcycle of 0.21 , which means that approximately 5 motorcycles positioned longitudinally between vehicles has the same effect of one passenger car on queue discharge. This result differs from the 0.33 value indicated by DENATRAN (2014). It is worth mentioning that the regression data considered only motorcycles positioned longitudinally between vehicles, not the motorcycles on the virtual lane, because the results of the $l_{1}$ analysis showed that the motorcycles on the virtual lane did not affect the discharge of the first four vehicles. If these motorcycles had been considered, the PCE factor would have been smaller. Independence, normality and homoscedasticity tests indicated that all these assumptions were met.

This study concluded that motorcycles affect the queue discharge of passenger cars and heavy vehicles, generating a reduction in road capacity in serving these types of vehicles. However, the size of the motorcycle and the behavior of the driver contribute to increase the road capacity in terms of general traffic. This statement is supported by the obtained value of the PCE factor, which means that this mode requires about one fifth of the time that a passenger car needs to travel along the analyzed signalized approach.

\section{ACKNOWLEDGMENTS}

This study was financed in part by the Coordenação de Aperfeiçoamento de Pessoal de Nível Superior - Brasil (CAPES) - Finance Code 001", the National Council for Scientific and Technological Development (CNPq), and by the Fundação Cearense de Apoio ao Desenvolvimento Científico e Tecnológico (FUNCAP). The Authors acknowledge the financial support provided by these agencies. The authors are also grateful to Fortaleza Advanced Traffic Control Center (CTAFOR) for providing the video recordings of the intersection.

\section{REFERENCES}

Agbolosu-amison, S. J.; A. W. Sadek and W. Eldessouk (2004) Inclement weather and traffic flow at signalized intersections. Transportation Research Record: Journal of the Transportation Research Board, Washington, D. C., v. 1867, pp. 163-171, 2004. DOI: 10.3141/1867-19.

Anusha, C. S.; A. Verma; Aff. M. ASCE and G. Kavitha (2013) Effects of two-wheelers on saturation flow at signalized intersections in developing countries. Journal of Transportation Engineering, vol. 139, pp. 448-457. DOI: 10.1061/(ASCE)TE.19435436.0000519 .

Berger, P. P. (2014) Estudo dos acidentes com motocicletas e da gravidade das lesões recorrentes. Dissertação de Mestrado, Universidade Federal do Espírito Santo, Vitória, 2014. Available on: < https://repositorio.ufes.br/bitstream/10/3980/1/tese_8491_Disserta\%C3\%A7\%C3\%A3o\%20-\%20Pedro\%20Pelacani\%20Berger\%20Vers\%C3\%A3o\%20Impress\%C3\%A3o.pdf> (Accessed on: 09/04/2020).

Bonneson, J. A. (1992) Study of Headway and Lost Time at Single-Point Urban Interchanges. Transportation Research Record: Journal of the Transportation Research Board, Washington, D.C., v. 1365, pp. 30-39, 1992. Available on: <http://onlinepubs.trb.org/Onlinepubs/trr/1992/1365/1365.pdf\#page=36>. (Accessed on: 09/04/2020).

Coutinho, C. H. L.; F. J. C. Cunto and S. M. P Ferreira (2015) Análise da severidade dos acidentes com motocicletas utilizando modelos probit e logit ordenados. TRANSPORTES, v. 23, n. 3, 2015. DOI: 10.14295/transportes.v23i4.926.

DENATRAN (2014). Manual Brasileiro de Sinalização de Trânsito Volume V-Sinalização Semafórica. Departamento Nacional de Trânsito, Brasília. Available in: < http://infraestrutura.gov.br/images/Educacao/Publicacoes/Manual_VOL_V_(2).pdf> (Accessed on: 09/04/2020).

Elefteriadou, L. (2014) An Introduction to Traffic Flow Theory. Ed. Springer, New York.

Holz, R. F. (2014) Realidade da motocicleta no ambiente urbano com foco no Brasil. Doctoral Thesis, Escola de Engenharia, Universidade Federal do Rio Grande do Sul, 2014. Available in: < http://lume.ufrgs.br/handle/10183/108507> (Accessed on: 09/04/2020).

Khosla, K. and J. C. Williams (2006) Saturation flow at signalized intersections during longer green time. Transportation Research Record: Journal of the Transportation Research Board, Washington, D.C., v. 1978, pp. 61-67. DOI: 10.3141/1978-10.

Le, X.; J. J. Lu; E. A. Mierzejewski and Y. Zhou (2000) Variations in capacity at signalized intersections with different area types. Transportation Research Record: Journal of the Transportation Research Board, Washington, D. C., v. 1710, pp. 199-204. DOI: $10.3141 / 1710-23$.

Lu, J. J. and J. C. Pernía (2000) The differences of driving behavior among different driver age groups at signalized intersections. IATSS Research, vol. 24, pp. 75-84. DOI: 10.1016/s0386-1112(14)60031-5.

Mânica, A. G. (2007) Modelo de previsão de acidentes rodoviários envolvendo motocicletas. M.Sc. Dissertation, Escola de Engenharia, Universidade Federal do Rio Grande do Sul. Available on: < http://lume.ufrgs.br/handle/10183/11172>. (Acessed on: 09/04/2020). 
Martins, E. T.; A. F. Boing and M. A. Peres (2013) Mortalidade por acidentes de motocicleta no Brasil: análise de tendência temporal, 1996-2009. Revista de Saúde Pública, vol. 47, n.5, pp. 931-941. DOI:10.1590/S0034-8910.2013047004227.

Mihn, C. C. and K. Sano (2003) Analysis of motorcycles effects to saturation flow rate at signalized intersection in developing countries. Journal of Eastern Asia Society for Transportation Studies, vol. 5, pp. 1211-1222.

Nakatsuji, T.; N. G. Hai and Y. Tanaboriboon (2001) Effects of motorcycle on capacity of signalized intersections. Journal of Infrastructure Planning, vol. 18, n. 5, pp. 935-942. DOI: 10.2208/journalip.18.935.

Radhakrishnan, S. and G. Ramadurai (2015) Discharge headway model for heterogeneous traffic conditions. Transportation Research Procedia, vol. 10, pp. 145-154. DOI: 10.1016/j.trpro.2015.09.064.

Rongviriyapanich, T. and C. Suppattrakul (2005) Effects of motorcycles on traffic operations on arterial streets. Journal of Eastern Asia Society for Transportation Studies, vol. 6, pp. 137-146. DOI: 10.11175/easts.6.137.

TRB (2010) Highway Capacity Manual. Transportation Research Board, v. 3, Washington. 